\title{
Maximising electro-mechanical response by minimising grain-scale strain heterogeneity in phase-change actuator ceramics
}

Oddershede, Jette; Hossain, Mohammad Jahangir; Daniels, John E.

Published in:

Applied Physics Letters

Link to article, DOI:

$10.1063 / 1.4961533$

Publication date:

2016

Document Version

Publisher's PDF, also known as Version of record

Link back to DTU Orbit

Citation (APA):

Oddershede, J., Hossain, M. J., \& Daniels, J. E. (2016). Maximising electro-mechanical response by minimising grain-scale strain heterogeneity in phase-change actuator ceramics. Applied Physics Letters, 109(9), [092901]. https://doi.org/10.1063/1.4961533

\section{General rights}

Copyright and moral rights for the publications made accessible in the public portal are retained by the authors and/or other copyright owners and it is a condition of accessing publications that users recognise and abide by the legal requirements associated with these rights.

- Users may download and print one copy of any publication from the public portal for the purpose of private study or research.

- You may not further distribute the material or use it for any profit-making activity or commercial gain

- You may freely distribute the URL identifying the publication in the public portal 


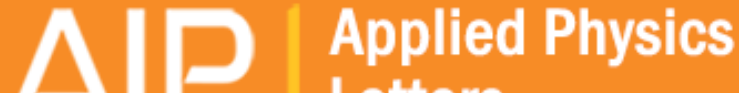 Letters}

\section{Maximising electro-mechanical response by minimising grain-scale strain heterogeneity in phase-change actuator ceramics}

Jette Oddershede, Mohammad Jahangir Hossain, and John E. Daniels

Citation: Applied Physics Letters 109, 092901 (2016); doi: 10.1063/1.4961533

View online: http://dx.doi.org/10.1063/1.4961533

View Table of Contents: http://scitation.aip.org/content/aip/journal/apl/109/9?ver=pdfcov

Published by the AIP Publishing

\section{Articles you may be interested in}

Temperature-dependent electro-mechanical actuation sensitivity in stiffness-tunable

$\mathrm{BaTiO3/polydimethylsiloxane} \mathrm{dielectric} \mathrm{elastomer} \mathrm{nanocomposites}$

Appl. Phys. Lett. 106, 092904 (2015); 10.1063/1.4914012

Universal scaling and intrinsic classification of electro-mechanical actuators

J. Appl. Phys. 113, 144906 (2013); 10.1063/1.4798365

Very high remnant polarization and phase-change electromechanical response of $\mathrm{BiFeO} 3-\mathrm{PbTiO} 3$ at the multiferroic morphotropic phase boundary

Appl. Phys. Lett. 101, 172908 (2012); 10.1063/1.4764537

Phase transition and piezoelectric property of ( $\mathrm{Bi} 0.5 \mathrm{Na} 0.5$ ) $0.94 \mathrm{Ba} 0.06 \mathrm{Zr}$ y Ti $1-$ y O 3 ( y= $0-0.04$ ) ceramics

J. Appl. Phys. 102, 094102 (2007); 10.1063/1.2803725

High T c lead-free Ba Ti O 3 - ( $\mathrm{Bi} 1 / 2 \mathrm{Na} 1 / 2$ ) Ti O 3 positive temperature coefficient of resistivity ceramics with electrically heterogeneous structure

Appl. Phys. Lett. 91, 162904 (2007); 10.1063/1.2799878

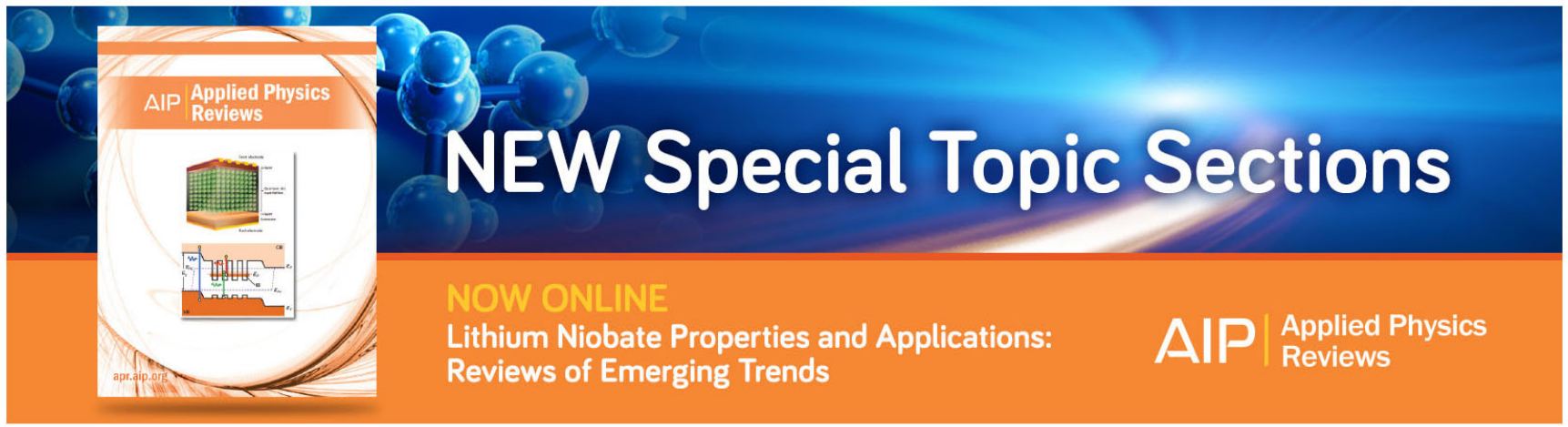




\title{
Maximising electro-mechanical response by minimising grain-scale strain heterogeneity in phase-change actuator ceramics
}

\author{
Jette Oddershede, ${ }^{1}$ Mohammad Jahangir Hossain, ${ }^{2}$ and John E. Daniels ${ }^{2}$ \\ ${ }^{1}$ NEXMAP, DTU Physics, 2800 Kongens Lyngby, Denmark \\ ${ }^{2}$ School of Materials Science and Engineering, UNSW Australia, Sydney, New South Wales 2052, Australia
}

(Received 18 July 2016; accepted 11 August 2016; published online 29 August 2016)

\begin{abstract}
Phase-change actuator ceramics directly couple electrical and mechanical energies through an electric-field-induced phase transformation. These materials are promising for the replacement of the most common electro-mechanical ceramic, lead zirconate titanate, which has environmental concerns. Here, we show that by compositional modification, we reduce the grain-scale heterogeneity of the electro-mechanical response by $40 \%$. In the materials investigated, this leads to an increase in the achievable electric-field-induced strain of the bulk ceramic of $45 \%$. Compositions of $(100-\mathrm{x}) \mathrm{Bi}_{0.5} \mathrm{Na}_{0.5} \mathrm{TiO}_{3}-(\mathrm{x}) \mathrm{BaTiO}_{3}$, which initially possess a pseudo-cubic symmetry, can be tuned to undergo phase transformations to combined lower symmetry phases, thus decreasing the anisotropy of the transformation strain. Further, modelling of transformation strains of individual grains shows that minimum grain-scale strain heterogeneity can be achieved by precise control of the lattice distortions and orientation distributions of the induced phases. The current results can be used to guide the design of next generation high-strain electro-mechanical ceramic actuator materials. Published by AIP Publishing. [http://dx.doi.org/10.1063/1.4961533]
\end{abstract}

In the search for lead-free replacement materials for the ubiquitous electro-ceramic lead zirconate titanate (PZT), much progress has been made. Many compositions are now available, which cover ranges of environmental and property requirements. ${ }^{1,2}$ This work has also resulted in a much further developed understanding of the structural mechanisms spanning several length scales that give rise to electromechanical coupling.

For the discovery of new actuator materials, maximising the achievable electric-field-induced strain is an obvious first step in the design process. This is usually approached by compositional modification, which involves producing solid solutions of two ferroelectric phases with unique symmetries or polar directions, in the hope of maximising properties at morphotropic phase boundaries (MPBs), analogous to the property enhancement observed in MPB compositions of PZT. While the exact mechanism of property enhancement in PZT is still the matter of some debate, this approach has successfully found many useful lead-free piezoelectric compositions. ${ }^{3}$ Microstructural engineering has also been applied to enhance piezoelectric performance in lead-free systems. This can be done by crystallographic texturing ${ }^{4}$ ceramic-ceramic composites $^{5,6}$ or core-shell grain structures. ${ }^{7}$ Generally, these methods require more complicated processing controls than standard polycrystalline ceramic processing, and thus increase the expense of the final material.

In addition to maximising the magnitude of the piezoelectric response, another critical design parameter is reproducibility and reliability of the material response over the lifetime of devices constructed from them. These properties can be correlated with the grain-scale strain heterogeneity experienced within the polycrystal during actuation. Large strain heterogeneities will lead to stress concentrations, the initiation of cracks, and inevitable failure of the material. Depending on the actuation mechanisms within a specific ceramic material, the stress concentrations may vary significantly. They are related to the degree of anisotropy of the intrinsic and extrinsic strain responses of the individual grains, as well as the elastic compliance anisotropy and its ability to compensate for strain heterogeneities at the grain scale.

An interesting sub-class of materials that have been discovered via the compositional modification route are those that appear to have cubic symmetry over a small compositional range at the MPB. This has been observed within several perovskite solid solutions; for instance, $\mathrm{Bi}_{0.5} \mathrm{Na}_{0.5} \mathrm{TiO}_{3}$ (BNT) produced with (among others) either $\mathrm{BaTiO}_{3}$ (BT), $\mathrm{Bi}_{0.5} \mathrm{~K}_{0.5} \mathrm{TiO}_{3}(\mathrm{BKT}),{ }^{9} \mathrm{~K}_{0.5} \mathrm{Na}_{0.5} \mathrm{NbO}_{3}(\mathrm{KNN}),{ }^{10}$ or combinations thereof. ${ }^{11-17}$ An applied electric field transforms these systems to either one (or a mixture of) lower symmetry phase(s) and results in a large electric-field-induced strain, observed to be as high as $0.4 \%{ }^{18}$ These transformations are unique when compared to the conventional strain mechanisms observed in PZT based materials. ${ }^{19-21}$ The transformations may in fact offer significantly larger strain ranges, as are available in single crystal materials which undergo fieldinduced phase transformations. ${ }^{22,23}$ The observed phase transformations in these ceramics are irreversible in some compositions and environmental conditions, but reversible at others, ${ }^{24}$ thus giving the opportunity of harnessing this transformation strain in a ceramic material for reversible actuation purposes. One difficulty with these materials, however, is that in the polycrystalline form, the achievable strain for a given induced phase symmetry is highly anisotropic. This leads to large grain-scale strain heterogeneity and likely poor component lifetimes.

Here, the (100-x) $\mathrm{Bi}_{0.5} \mathrm{Na}_{0.5} \mathrm{TiO}_{3}-(\mathrm{x}) \mathrm{BaTiO}_{3}(\mathrm{BNT}-\mathrm{xBT})$ material system is investigated for $\mathrm{x}$ between 5.75 and 8 , where sample compositions appear metrically cubic when processed. After the application of an electrical field, lower 


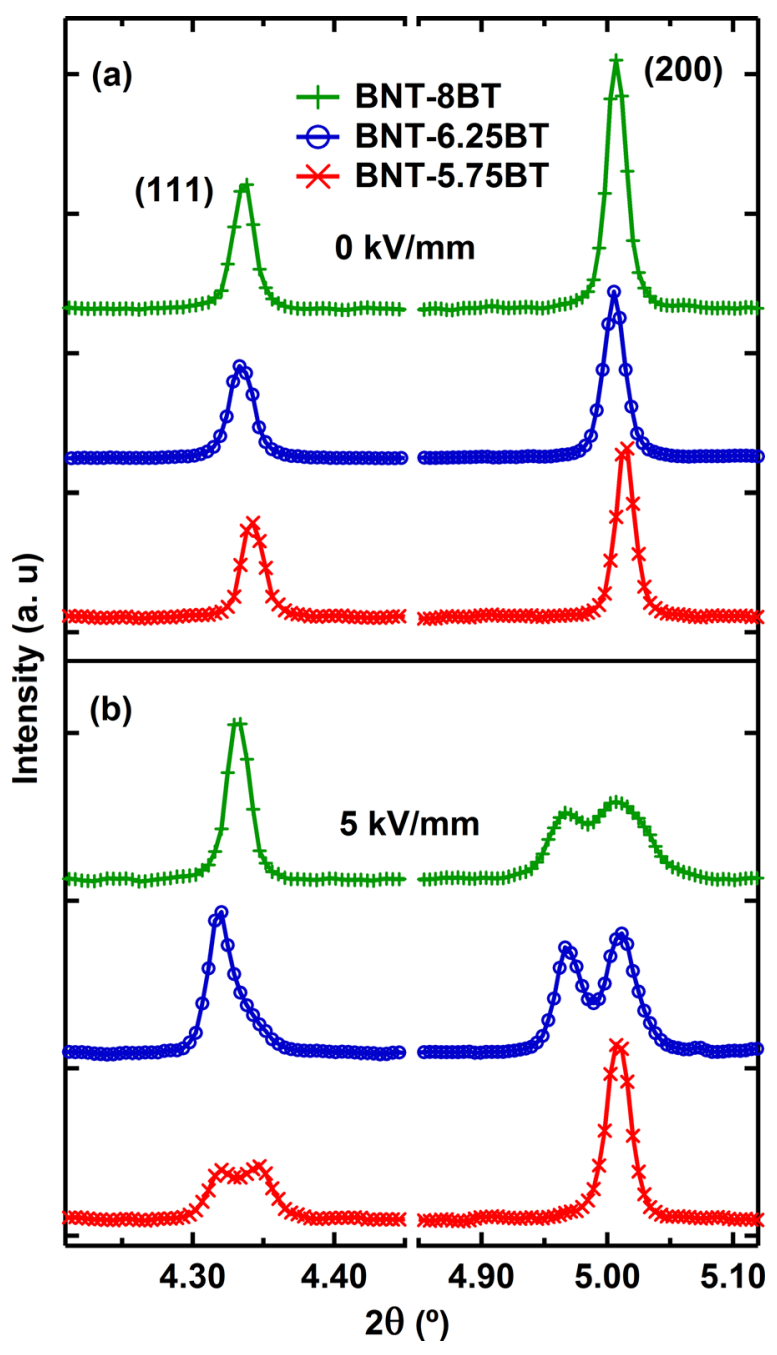

FIG. 1. Diffraction intensities with the scattering vector parallel to the electric-field vector. At the initial state (a) all compositions appear pseudocubic. At $5 \mathrm{kV} / \mathrm{mm}$ (b) BNT-5.75BT transforms to a single rhombohedral phase, BNT-6.25BT transforms to a mixed rhombohedral and tetragonal phase structure, and BNT-8BT transforms to a single tetragonal phase.

symmetry rhombohedral and tetragonal phases, as well as a mixture of these are observed..$^{25,26} \mathrm{X}$-ray powder diffraction is used to determine the lattice distortions and phase fractions of the resulting phases. These parameters are then used as input to modelling of the transformation strains of individual grains to investigate how lattice distortions affect the average strain response and grain-scale strain heterogeneity. Further modelling demonstrates that precise control of the lattice distortions of the resultant phases in the transformed mixed-phase state allows potential improvements in the properties of the next generation of phase-change actuator ceramics.
Disc-shaped BNT-xBT (where $\mathrm{x}=5.75,6.25$, and 8) samples were prepared by the solid-state synthesis route. ${ }^{27}$ Samples were sintered at $1130{ }^{\circ} \mathrm{C}$ for $3 \mathrm{~h}$ in an air atmosphere with temperature ramp rates of $5^{\circ} \mathrm{C} / \mathrm{min}$. Bar-shaped samples with dimensions of approximately $1 \times 1 \times 6 \mathrm{~mm}^{3}$ were cut from the ceramic discs for the high energy X-ray diffraction experiment. Annealing was carried out at $400{ }^{\circ} \mathrm{C}$ for around $30 \mathrm{~min}$ to remove any residual stresses from the cutting and polishing process. Silver electrodes were applied to two parallel $1 \times 6 \mathrm{~mm}^{2}$ surfaces of the sample bar.

High energy X-ray diffraction experiments were carried out at beamline ID15 of the European Synchrotron Radiation Facility. A beam energy of $72.7 \mathrm{keV}$ (wavelength, $\lambda=0.1705 \AA$ ) was used to penetrate the sample cross-section and measure the diffracted signal from the bulk of the sample. Diffraction patterns were collected using a Pixium flat panel detector. ${ }^{28}$ An in situ electric field cell allowed for the application of electric field cycles while acquiring structural data. ${ }^{29}$ Details of this experimental technique can be found elsewhere. ${ }^{30}$ The two-dimensional detector images collected were integrated into 36 angular segments using the software package FIT2D ${ }^{31}$ in order to obtain one-dimensional diffraction patterns. These extracted patterns represent diffraction information collected with scattering vector aligned from approximately parallel to perpendicular to the applied electric field vector. The lattice parameters and phase fractions for the selected sample compositions were determined by combined texture and Rietveld refinements using the program MAUD. ${ }^{32}$

The initial phase of all samples in the composition range was determined to be pseudo-cubic, with no observable diffraction peak splitting or asymmetry over the measured $2 \theta$ range, as shown in Figure 1(a). Upon application of an electric field, the three chosen compositions show unique induced structures. BNT-5.75BT transforms to a single phase rhombohedral structure, BNT-6.25BT transforms to a phase mixture of rhombohedral and tetragonal structures, and BNT-8BT transforms to a single phase tetragonal structure, see Figure 1(b). A summary of the induced unit cells is provided in Table I.

Simulations of transformation strains were performed for 1000 randomly oriented grains of pseudo-cubic symmetry. ${ }^{33}$ Both tetragonal and rhombohedral distortions of the pseudo-cubic cell were assumed for the simulations. Lattice constants corresponding to those experimentally determined for the mixed phase BNT-6.25BT sample were used, as these represent the actual lattice distortions in a mixed phase system where transformation strains play an important role in

TABLE I. Lattice parameters and phase fractions derived from the powder diffraction experiments. Error bars on the reported values are below the final significant digit reported.

\begin{tabular}{|c|c|c|c|c|c|c|c|}
\hline \multirow[b]{2}{*}{ Sample } & \multicolumn{2}{|c|}{ Initial } & \multicolumn{5}{|c|}{ At field } \\
\hline & Phase & $a_{0}(\AA)$ & Phase & $a(\AA)$ & $c(\AA)$ & $\alpha_{\mathrm{r}}(\mathrm{deg})$ & Phase fraction \\
\hline BNT-5.75BT & Pseudo-cubic & 3.8962 & Rhombohedral (R3c) & 7.7923 & $\ldots$ & 89.79 & 1.00 \\
\hline \multirow[t]{2}{*}{ BNT-6.25BT } & Pseudo-cubic & 3.904 & Rhombohedral (R3c) & 7.7932 & $\ldots$ & 89.78 & 0.72 \\
\hline & & & Tetragonal (P4 mm) & 3.8875 & 3.9317 & $\ldots$ & 0.28 \\
\hline BNT-8BT & Pseudo-cubic & 3.9029 & Tetragonal (P4 mm) & 3.8973 & 3.925 & $\ldots$ & 1.00 \\
\hline
\end{tabular}



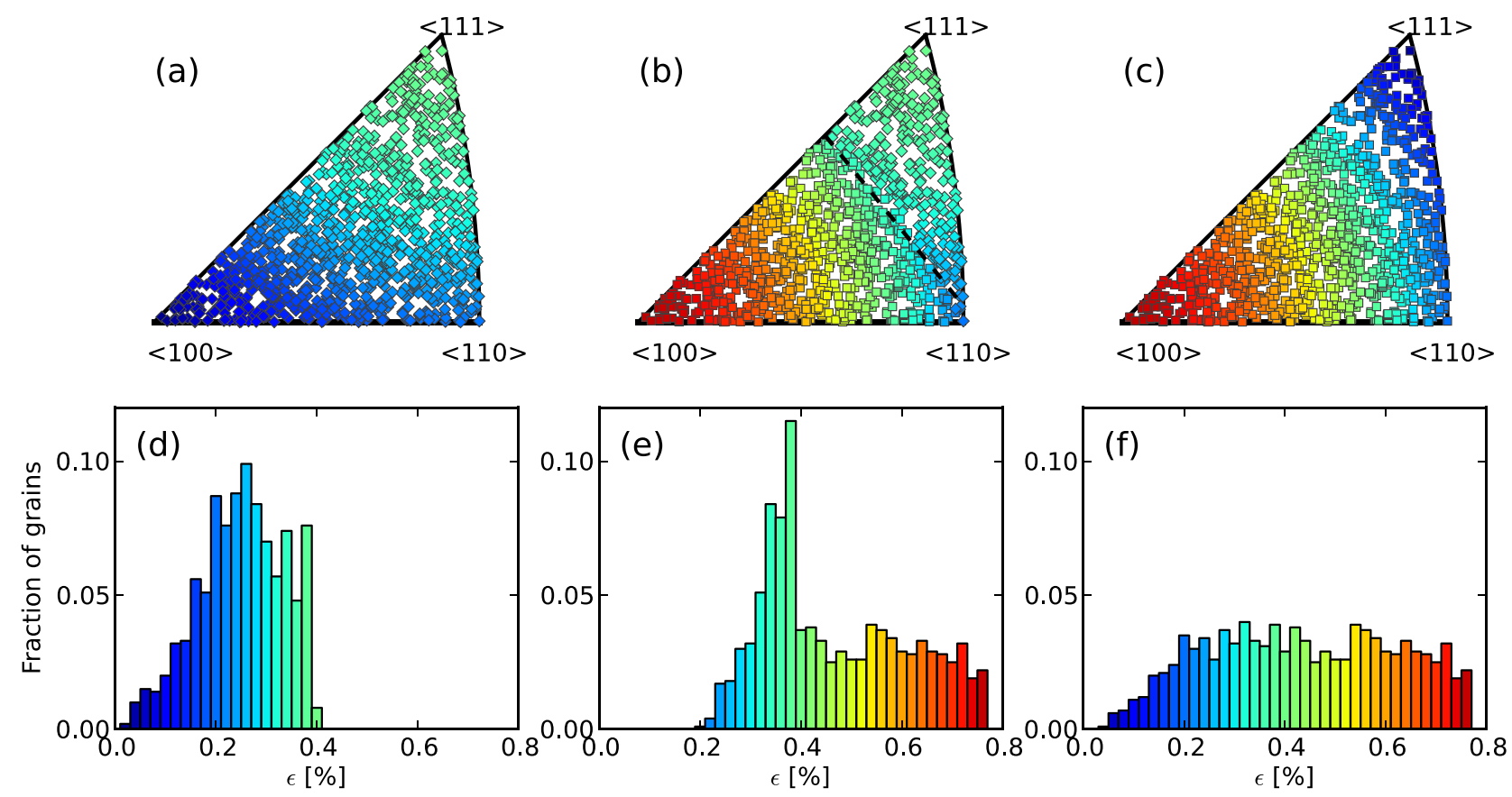

FIG. 2. Simulated phase transformation strains for the saturated domain texture state for a pure rhombohedral transformation (a), a mixed rhombohedral/tetragonal transformation (b), and a pure tetragonal transformation (c). Associated histograms showing the fraction of grains achieving a given transformation strain magnitude are shown in (d)-(f), respectively.

the material behaviour. The transformation strains were calculated by assuming full occupancy of the transformed rhombohedral ${ }^{34}$ or tetragonal ${ }^{35}$ domain variant whose polarisation axis was most closely aligned to the electric field direction, i.e., for the saturated domain texture state.

The simulated transformation strain distributions as a function of orientation are shown in Figures 2(a)-2(c) for pure rhombohedral, mixed phase, and pure tetragonal induced phases, respectively. From these data, the fraction of grains with a given magnitude of transformation strain can be found for each transformation type, and are shown in Figures 2(d)-2(f). For the mixed phase rhombohedral/tetragonal material (Figures 2(b) and 2(e)), it was assumed that each grain transforms to the phase that corresponds to the largest transformation strain along the electric field vector. For instance, with the present lattice distortions, a $\langle 110\rangle$-oriented grain would result in a tetragonal transformation strain of $0.25 \%$, while the rhombohedral transformation strain would be $0.19 \%$. Hence, a $\langle 110\rangle$-oriented grain is assumed to transform from pseudo-cubic to tetragonal symmetry.

The maximum achievable transformation strain in the simulation based on the BNT-6.25BT lattice parameters presented in Figure 2 is $\varepsilon_{\max }^{\mathrm{r}}=\pi\left(0.5-\alpha_{\mathrm{r}} / 180^{\circ}\right)=0.38 \%$ for rhombohedral $^{34}$ and $\varepsilon_{\max }^{\mathrm{t}}=2(c-a) /\left(3 a_{0}\right)=0.75 \%$ for tetragonal $^{35}$ symmetry. From the above, it is obvious that the mixed phase volume fractions, as well as the average and width of the transformation strain distributions, are intimately linked to the rhombohedral and tetragonal lattice distortions.

Figure 3(a) shows the average and width of the mixed phase transformation strain distribution as a function of the rhombohedral volume fraction obtained by varying the lattice distortions in the simulations. The plot corresponds to 750 different combinations of lattice parameters, each applied to the same 1000 randomly generated grain orientations. The
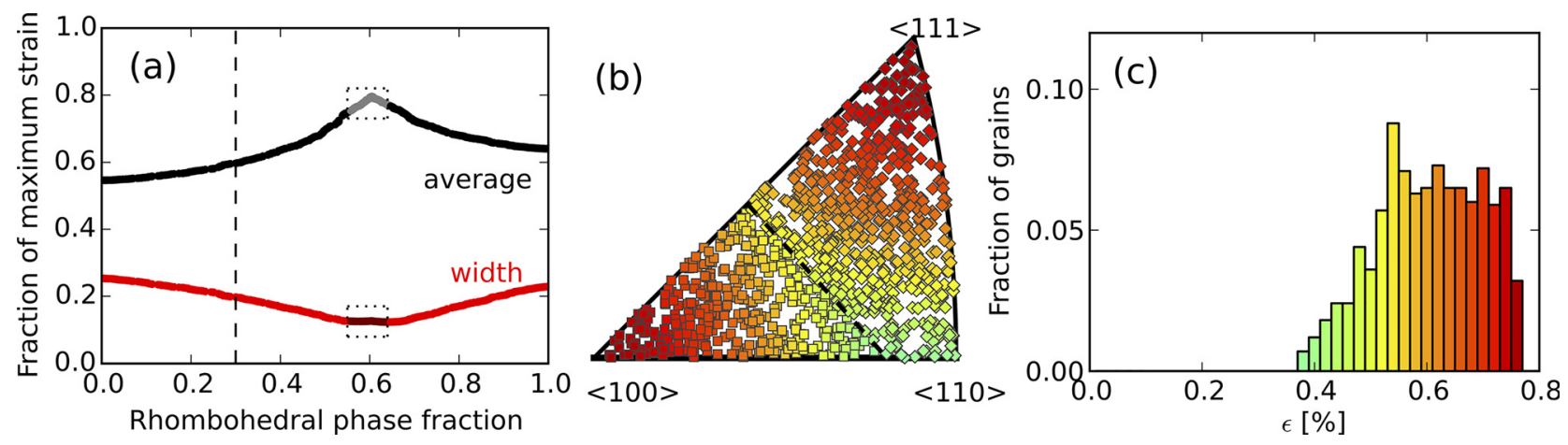

FIG. 3. (a) Simulated variation in the transformation strain distribution average (black) and width (red) given as fractions of the maximum achievable transformation strain in both phases when varying the phase fraction content from pure tetragonal to pure rhombohedral. (b) Simulated transformation strain magnitudes for the saturated domain texture state for mixed phase rhombohedral/tetragonal transformation with the same maximum achievable transformation strain in both phases. The associated histogram showing the fraction of grains achieving a given transformation strain magnitude is shown in (c). 
rhombohedral angle was varied in 30 steps between $90.00^{\circ}$ $\left(\varepsilon_{\max }^{\mathrm{r}}=0.0 \%\right)$ and $88.55^{\circ}\left(\varepsilon_{\max }^{\mathrm{r}}=2.5 \%\right)$, while the tetragonal lattice distortion was modelled assuming the same pseudocubic unit cell $a_{0}=3.904 \AA$ for the undistorted reference (initial state BNT-6.25BT, Table I), a constant volume of the distorted tetragonal unit cell (at field value for BNT-6.25BT), and $c / a$ ratios varying in 25 steps between $1.000\left(\varepsilon_{\max }^{\mathrm{t}}=0.0 \%\right)$ and $1.038\left(\varepsilon_{\max }^{\mathrm{t}}=2.5 \%\right)$. All averages and widths of the transformation strain distributions are reported as fractions of the maximum achievable transformation strain for the particular combination of lattice parameters, thus either for a $\langle 111\rangle$ oriented rhombohedral or a $\langle 100\rangle$-oriented tetragonal grain.

From Figure 3(a), a minimum in the width of the non- $180^{\circ}$ domain switching strain distribution, and hence a minimum in the grain-scale strain heterogeneity, is clearly observed for a rhombohedral domain fraction of roughly 0.6. This fraction reflects the fact that a unit cell contains four independent $\langle 111\rangle$ directions and only three $\langle 100\rangle$ directions; thus, a grain of random orientation is more likely to have the poling axis aligned with $\langle 111\rangle$ than with $\langle 100\rangle$. The highlighted section around the minimum grain-scale strain heterogeneity in Figure 3(a) corresponds to less than $10 \%$ relative difference between the maximum achievable transformation strain in the rhombohedral and tetragonal phases; thus, the simulations clearly indicate that the maximum average transformation strain and minimum grainscale strain heterogeneity for these mixed-phase materials can be achieved when the lattice distortions are balanced to give $\varepsilon_{\max }^{\mathrm{r}} \approx \varepsilon_{\max }^{\mathrm{t}}$. Figures 3(b) and 3(c) show an example of the simulated materials transformation strain magnitudes and distributions for the case where $\varepsilon_{\max }^{\mathrm{r}}=\varepsilon_{\max }^{\mathrm{t}}=0.75 \%$, respectively. To achieve this, the simulation was performed with the tetragonal lattice parameters of BNT-6.25BT (Figures 2(c) and 2(f)) and $\alpha_{\mathrm{r}}=89.57^{\circ}$.

The marked rhombohedral phase fraction of 0.30 in Figure 3(a) corresponds to the simulation example in Figure 2; a mixed phase transformation strain distribution with an average of $0.46 \%$ and a width of $0.14 \%$ compared to $\varepsilon_{\max }^{\mathrm{t}}$ $=0.75 \%$. The experimentally determined lattice parameters of BNT-6.25BT were used as input for this simulation, yet the resulting rhombohedral domain volume fraction was far from the experimentally determined value of 0.72 . This serves to illustrate that the assumptions behind the model, i.e., that the grain will transform to the single domain variant that gives maximum strain along the electric field direction (the saturated domain texture state), are not valid for all compositions. ${ }^{36}$ In fact, previous work has shown that the evolution of the phase fraction of tetragonal or rhombohedral symmetries in the BNT-xBT series varies with composition and field strength. ${ }^{37-39}$

One factor that may have a significant influence on these results is that here only the orientation and not the spatial distribution of grains was taken into account in the simulations, and thus the effects of intergranular stresses were ignored. It has recently been observed by means of three-dimensional $\mathrm{X}$-ray diffraction (3DXRD) that similarly oriented grains of (0.82) $\mathrm{Bi}_{0.5} \mathrm{Na}_{0.5} \mathrm{TiO}_{3}-(0.18) \mathrm{Bi}_{0.5} \mathrm{~K}_{0.5} \mathrm{TiO}_{3}$ (a randomly textured pseudo-cubic material in the as-processed state that transforms to a majority rhombohedral phase upon application of an electric field) show considerable variations in electric-fieldinduced domain volume fractions and hence transformation strains, ${ }^{40}$ an observation that was attributed to local grain interaction effects. Likewise, in a recent self-consistent micromechanical model for the behaviour of ferroelectric polycrystalline materials under electro-mechanical loading, it was shown for an isotropic polycrystal that the average internal stress remains equal to the macroscopic stress whatever the level of applied electric field, but the local stress levels are getting higher as the electric field increases. ${ }^{41}$ The exact nature of these local effects is unknown; however, interaction of ferroic domains at grain boundaries and the coupling of extrinsic ferroelectric/ferroelastic strains with the elastic anisotropy of the system are suspected to have an influence. Further development of grain-scale microscopy methods based on $3 \mathrm{DXRD},{ }^{42,43}$ diffraction contrast tomography, ${ }^{44-46}$ darkfield X-rays, ${ }^{47,48}$ or transmitted electrons ${ }^{49}$ will allow the possibility to establish three-dimensional grain neighbour relations experimentally, quantify intergranular interactions (in particular, stresses and strains, both intrinsic and extrinsic), and build these into predictive models. ${ }^{50-52}$ Development of these characterisation techniques and predictive modelling covering multiple length scales may be the key tools needed in order to design new reversible phase-change actuator ceramics with improved fatigue properties compared to present generation ceramics. ${ }^{17,53-55}$

The present study has shown that minimum grain-scale strain heterogeneity can be achieved by precise control of the lattice distortions of the resultant phases in the transformed state and that this in turn leads to the maximum achievable transformation strain. Designing materials to have controlled combinations of transformation symmetries and unit cell distortions may be challenging. Nonetheless, previous compositional dependent studies have paved the way by showing that some degree of control over both resultant phases, lattice distortions, and reversibility of the electric-field-induced transformation can be achieved, and they may also serve as inspiration as to within which compositions and environmental conditions to start the search for new materials. This work provides a set of design tools that may be useful when searching for high-strain electroceramic actuator materials using both experimental and theoretical approaches.

J.O. acknowledges financial support from the Danish Independent Research Council | Technology and Production Sciences Case No. 12-127449. J.E.D. acknowledges financial support from Australian Research Council Discovery Project Nos. DP120103968 and DP130100415. The European Synchrotron Radiation Facility is thanked for providing beam time for the experiment.

${ }^{1}$ J. Rödel, W. Jo, K. T. P. Seifert, E.-M. Anton, and T. Granzow, J. Am. Ceram. Soc. 92, 1153 (2009).

${ }^{2}$ J. Rödel, K. G. Webber, R. Dittmer, W. Jo, and M. Kimura, J. Eur. Ceram. Soc. 35, 1659 (2015).

${ }^{3}$ C.-H. Hong, H.-P. Kim, B.-Y. Choi, H.-S. Han, J. S. Son, C. W. Ahn, and W. Jo, J. Mater. 2, 1 (2016).

${ }^{4}$ Y. Saito, H. Takao, T. Tani, T. Nonoyama, K. Takatori, T. Homma, T. Nagaya, and M. Nakamura, Nature 432, 84 (2004).

${ }^{5}$ D. Su Lee, S. Jong Jeong, M. Soo Kim, and J. Hyuk Koh, J. Appl. Phys. 112, 124109 (2012).

${ }^{6}$ N. H. Khansur, C. Groh, W. Jo, C. Reinhard, J. A. Kimpton, K. G. Webber, and J. E. Daniels, J. Appl. Phys. 115, 124108 (2014). 
${ }^{7}$ S. Y. Choi, S. J. Jeong, D. S. Lee, M. S. Kim, J. S. Lee, J. H. Cho, B. I. Kim, and Y. Ikuhara, Chem. Mater. 24, 3363 (2012).

${ }^{8}$ T. Takenaka, K. Maruyama, and K. Sakata, Jpn. J. Appl. Phys., Part 1 30, 2236 (1991).

${ }^{9}$ A. Sasaki, T. Chiba, Y. Mamiya, and E. Otsuki, Jpn. J. Appl. Phys., Part 1 38, 5564 (1999).

${ }^{10}$ A. B. Kounga, S.-T. Zhang, W. Jo, T. Granzow, and J. Rödel, Appl. Phys. Lett. 92, 222902 (2008).

${ }^{11}$ H. Nagata, M. Yoshida, Y. Makiuchi, and T. Takenaka, Jpn. J. Appl. Phys., Part 1 42, 7401 (2003).

${ }^{12}$ Y. Makiuchi, R. Aoyagi, Y. Hiruma, H. Nagata, and T. Takenaka, Jpn. J. Appl. Phys., Part 1 44, 4350 (2005).

${ }^{13}$ J. Shieh, K. C. Wu, and C. S. Chen, Acta Mater. 55, 3081 (2007).

${ }^{14}$ T. R. Shrout and S. J. Zhang, J. Electroceram. 19, 113 (2007).

${ }^{15}$ S.-T. Zhang, A. B. Kounga, E. Aulbach, H. Ehrenberg, and J. Rödel, Appl. Phys. Lett. 91, 112906 (2007).

${ }^{16}$ K. T. P. Seifert, W. Jo, and J. Rödel, J. Am. Ceram. Soc. 93, 1392 (2010).

${ }^{17}$ X. Liu and X. Tan, Adv. Mater. 28, 574 (2016).

${ }^{18}$ W. Jo, R. Dittmer, M. Acosta, J. Zang, C. Groh, E. Sapper, K. Wang, and J. Rödel, J. Electroceram. 29, 71 (2012).

${ }^{19}$ J. T. Reszat, A. E. Glazounov, and M. J. Hoffmann, J. Eur. Ceram. Soc. 21, 1349 (2001).

${ }^{20}$ D. A. Hall, A. Steuwer, B. Cherdhirunkorn, T. Mori, and P. J. Withers, J. Appl. Phys. 96, 4245 (2004).

${ }^{21}$ A. Pramanick, D. Damjanovic, J. E. Daniels, J. C. Nino, and J. L. Jones, J. Am. Ceram. Soc. 94, 293 (2011).

${ }^{22}$ S.-E. Park and T. R. Shrout, J. Appl. Phys. 82, 1804 (1997).

${ }^{23}$ S.-E. Park and T. R. Shrout, Mater. Res. Innovations 1, 20 (1997).

${ }^{24}$ M. Hinterstein, M. Knapp, M. Hölzel, W. Jo, A. Cervellino, H. Ehrenberg, and H. Fuess, J. Appl. Crystallogr. 43, 1314 (2010).

${ }^{25}$ J. E. Daniels, W. Jo, J. Rödel, and J. L. Jones, Appl. Phys. Lett. 95, 032904 (2009).

${ }^{26}$ H. Simons, J. Daniels, W. Jo, R. Dittmer, A. Studer, M. Avdeev, J. Rödel, and M. Hoffman, Appl. Phys. Lett. 98, 082901 (2011).

${ }^{27}$ W. Jo and J. Rödel, Appl. Phys. Lett. 99, 042901 (2011).

${ }^{28}$ J. E. Daniels and M. Drakopoulos, J. Synchrotron Radiat. 16, 463 (2009).

${ }^{29}$ J. E. Daniels, A. Pramanick, and J. L. Jones, IEEE Trans. Ultrason. Ferroelectr. Freq. Control 56, 1539 (2009).

${ }^{30}$ J. L. Jones, A. Pramanick, and J. E. Daniels, Appl. Phys. Lett. 93, 152904 (2008).

${ }^{31}$ A. P. Hammersley, S. O. Svensson, M. Hanfland, A. N. Fitch, and D. Hausermann, High Pressure Res. 14, 235 (1996).

${ }^{32}$ L. Lutterotti, M. Bortolotti, G. Ischia, I. Lonardelli, and H.-R. Wenk, Z. Kristallogr. Suppl. 26, 125 (2007).
${ }^{33}$ J. Oddershede, M. Majkut, Q. Cao, S. Schmidt, J. P. Wright, P. Kenesei, and J. E. Daniels, J. Appl. Crystallogr. 48, 882 (2015).

${ }^{34}$ D. A. Hall, A. Steuwer, B. Cherdhirunkorn, T. Mori, and P. J. Withers, Acta Mater. 54, 3075 (2006).

${ }^{35}$ D. A. Hall, A. Steuwer, B. Cherdhirunkorn, P. J. Withers, and T. Mori, Mater. Sci. Eng., A 409, 206 (2005).

${ }^{36}$ J. L. Jones, M. Hoffman, and K. J. Bowman, J. Appl. Phys. 98, 024115 (2005).

${ }^{37}$ J. E. Daniels, W. Jo, J. Rödel, V. Honkimäki, and J. L. Jones, Acta Mater. 58, 2103 (2010).

${ }^{38}$ C. Ma and X. Tan, J. Am. Ceram. Soc. 94, 4040 (2011).

${ }^{39}$ W. Jo, J. E. Daniels, J. L. Jones, X. Tan, P. A. Thomas, D. Damjanovic, and J. Rödel, J. Appl. Phys. 109, 014110 (2011).

${ }^{40}$ J. E. Daniels, M. Majkut, Q. Cao, S. Schmidt, J. P. Wright, and J. Oddershede, Sci. Rep. 6, 22820 (2016).

${ }^{41}$ L. Daniel, D. A. Hall, and P. J. Withers, Mech. Mater. 71, 85 (2014).

${ }^{42}$ S. Schmidt, S. F. Nielsen, C. Gundlach, L. Margulies, X. Huang, and D. Juul Jensen, Science 305, 229 (2004).

${ }^{43}$ S. Schmidt, U. L. Olsen, H. F. Poulsen, H. O. Sørensen, E. M. Lauridsen, L. Margulies, C. Maurice, and D. Juul Jensen, Scr. Mater. 59, 491 (2008).

${ }^{44}$ P. Reischig, A. King, L. Nervo, N. Viganó, Y. Guilhem, W. J. Palenstijn, K. J. Batenburg, M. Preuss, and W. Ludwig, J. Appl. Crystallogr. 46, 297 (2013).

${ }^{45}$ N. Viganó, W. Ludwig, and K. J. Batenburg, J. Appl. Crystallogr. 47, 1826 (2014).

${ }^{46}$ W. C. Lenthe, M. P. Echlin, A. Trenkle, and M. Syha, J. Appl. Crystallogr. 48, 1034 (2015).

${ }^{47}$ H. Simons, A. King, W. Ludwig, C. Detlefs, W. Pantleon, S. Schmidt, I. Snigireva, A. Snigirev, and H. F. Poulsen, Nat. Commun. 6, 6098 (2015).

${ }^{48}$ H. Simons, A. C. Jakobsen, S. R. Ahl, C. Detlefs, and H. F. Poulsen, MRS Bull. 41, 454 (2016).

${ }^{49}$ H. H. Liu, S. Schmidt, H. F. Poulsen, A. Godfrey, Z. Q. Liu, J. A. Sharon, and X. Huang, Science 332, 833 (2011).

${ }^{50}$ A. Haug, P. R. Onck, and E. Van der Giessen, Int. J. Solids Struct. 44, 2066 (2007).

${ }^{51}$ E.-M. Anton, R. E. García, T. S. Key, J. E. Blendell, and K. J. Bowman, J. Appl. Phys. 105, 024107 (2009).

${ }^{52}$ S. B. Lee, T. S. Key, Z. Liang, R. E. García, S. Wang, X. Tricoche, G. S. Rohrer, Y. Saito, C. Ito, and T. Tani, J. Eur. Ceram. Soc. 33, 313 (2013).

${ }^{53}$ Z. Luo, T. Granzow, J. Glaum, W. Jo, J. Rödel, and M. Hoffman, J. Am. Ceram. Soc. 94, 3927 (2011).

${ }^{54}$ Y. A. Genenko, J. Glaum, M. J. Hoffmann, and K. Albe, Mater. Sci. Eng., B 192, 52 (2015).

${ }^{55}$ Y. Zhang, J. Glaum, M. C. Ehmke, J. E. Blendell, K. J. Bowman, and M. J. Hoffman, J. Am. Ceram. Soc. 99, 174 (2016). 